J. Amer. Soc. Hort. Sci. 116(5):766-769. 1991.

\title{
Improved Methods of Mechanically Thinning Peaches at Full Bloom
}

\author{
Tara A. Baugher ${ }^{1}$ Kendall C. Elliott ${ }^{2}$, and David W. Leach ${ }^{1}$ \\ West Virginia University Experiment Farm, Kearneysville, WV 25430
}

B.D. Horton and Stephen S. Miller

Appalachian Fruit Research Station, U.S. Department of Agriculture, Agricultural Research

Service, Kearneysville, WV 25430

Additional index words. Prunus persica, abscission, fruit size

\begin{abstract}
Studies were conducted on peach [Prunus persica (L.) Batsch] during 1988 to 1990 to test the performance of a tree-width rope-curtain bloom thinner and a rotating rope-curtain thinner. Six trips over the tree canopy were required with the tree-width rope curtain, and only one trip was required with the rotating curtain to thin to a spacing of about one flower per $9 \mathrm{~cm}$ of fruiting shoot length. Based on the number of flowers per square centimeter of branch cross-sectional area (CSA) immediately following thinning and the number of fruit per square centimeter of CSA following June drop, rope-curtain thinning was equal to hand-thinning at full bloom (FB). Rope-curtain thinning reduced hand-thinning time by $40 \%$ and increased harvest fruit weight by $10 \%$ to $20 \%$. Research on various modifications in tree training/pruning indicated that performance of the mechanical thinner was negatively correlated with shoot density. Thinning was maximum on open-center-trained trees on which detailed pruning had been conducted to eliminate overlapping shoots.
\end{abstract}

Thinning peaches at bloom increases fruit size, flower bud formation, and, in general, revenue to the grower (Baugher et al., 1988; Byers, 1989; Byers and Lyons, 1985; Byers et al., 1990; Johnson and Handley, 1989). Although the standard commercial practice still is to thin peaches by hand at 40 to 60 days after full bloom (DAFB), hand-thinning at FB is becoming more common (Myers, 1986). Peach orchard profits can be further increased if hand bloom thinning is replaced by chemical or mechanical thinning. Byers and Lyons (1985) have shown that desiccating chemicals can be successfully used at FB to thin peaches; however, commercial registration of these chemicals remains questionable. Preliminary studies on mechanical bloom thinning with a rope curtain (Baugher et al., 1988) or a highpressure water stream (Byers, 1989) show promise, but the techniques need refinement.

Rope thinning was initially tested in West Virginia in 1987 (Baugher et al., 1988). Our research demonstrated that maximum thinning occurred when $80 \%$ to $100 \%$ of the blossoms were open and the tractor operated at $3.2 \mathrm{~km} \cdot \mathrm{h}^{-1}$. The most effective treatments removed $45 \%$ to $60 \%$ of the blossoms and reduced follow-up hand-thinning time by $30 \%$. Disadvantages of the 1987 test unit were: 1) multiple trips over the tree were required and 2) fewer flowers were removed in the lower third than in the upper part of the canopy.

Studies were conducted in 1988 to 1990 to test modifications of the rope-curtain thinner and also of tree training for potential effects on thinning. The objectives were to reduce the number of trips through the orchard, improve uniformity of thinning, reduce labor, and increase fruit size.

Received for publication 29 Nov. 1990. Approved for publication by the Director, West Virginia Agricultural and Forestry Expt. Sta. as Scientific Article no. 2255. We thank Sandra Walter, Gloria Nestor, Carolyn Kilmer, Otho Lewis, Ronald Lewis, and the experiment station staff for their valuable contributions toward this research. The cost of publishing this paper was defrayed in part by the payment of page charges. Under postal regulations, this paper therefore must be hereby marked advertisement solely to indicate this fact.

'Division of Plant and Soil Sciences.

${ }^{2}$ Division of Resource Management.

\section{Materials and Methods}

1988 Studies. A redesigned prototype machine for thinning peach bloom was evaluated in 1988. Modifications made to increase thinning rate and uniformity included using large-diameter $(3 \mathrm{~cm})$ manila rope and spacing the strands contiguously along the support frame $(30-\mathrm{cm}$ strands doubled over the support frame; width was adjusted by adding or removing strands of rope) (Fig. 1A). Trials were conducted at the U.S. Dept. of Agriculture, Agricultural Research Service Research Station, Bardane, W.Va., and the West Virginia Univ. Experiment Station, Kearneysville, on 'Redhaven' and 'Cresthaven' peach trees, respectively, and on three pruning/training systems. Trees within a location were full size, of uniform vigor, and, based on prebloom measurements, had similar flower densities. Trees at Bardane were trained to an open-center system and were $1.8 \mathrm{~m}$ high. The Kearneysville experiment was designed to compare 1 ) the standard open-center system ( $2.5 \mathrm{~m}$ in height) moderately pruned, 2) the standard open-center system pruned with detail to eliminate overlapping shoots, and 3) the Murrumbidgee Irrigation Areas (MIA) trellis, a split canopy system (Hutton and McFadyen, 1987).

Rope-curtain treatments with six passes per tree were compared to FB hand-thinned controls (spacing of one flower/15 $\mathrm{cm}$ of fruiting shoot length) and 50 DAFB hand-thinned controls. Three branches were tagged in the mid-O.5-m section of each tree canopy. Branch diameters were measured with a vernier caliper and the CSA was calculated. Treatments were compared using the number of flowers $/ \mathrm{cm}^{2}$ of CSA following thinning, the number of fruit $/ \mathrm{cm}^{2}$ of CSA following physiological June drop, and the average fruit size (by weight) at harvest. Followup hand-thinning times were also recorded. In the tree training/ pruning study, fruiting shoot length and flower count were determined in three, $0.3-\mathrm{m}^{3}$ regions/tree, and the data were subjected to regression analysis.

1989 Studies. A rotating thinner with four quarter-tree-width curtains was built in 1989 (Fig. 1B). Trials were conducted on the same 'Redhaven' and 'Cresthaven' trees used in 1988 and

Abbreviations: CSA, cross-sectional area; DAFB, days after full bloom; FB, full bloom. 


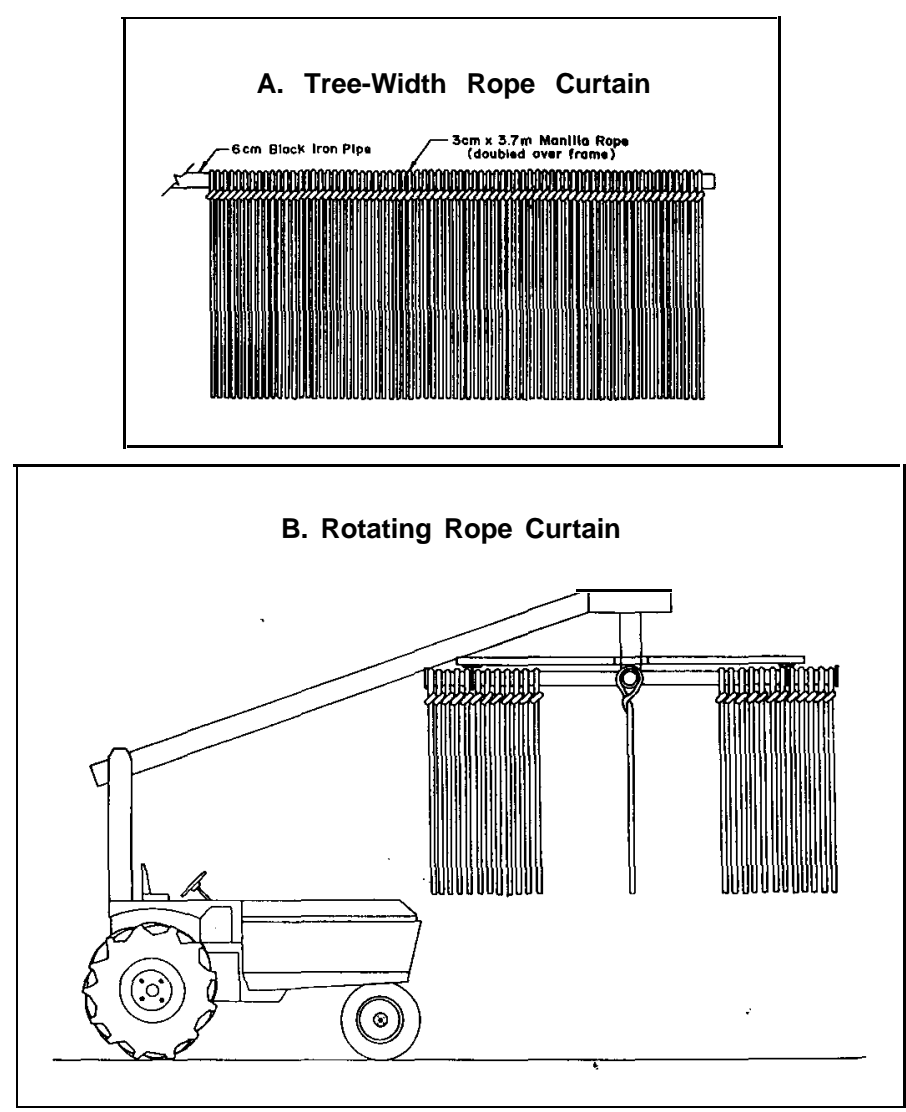

Fig.1. (A) Tree-width rope-curtain thinner tested in 1988 and 1989.

(B) Rotating rope-curtain thinner (four quarter-tree-width curtains on rotating frame) tested in 1989 and 1990.

on 'Loring' at Kearneysville. Trees were trained to a standard open-center system and moderately pruned. The rotating thinner was compared with the tree-width rope curtain, thinning with $\left(\mathrm{NH}_{4}\right)_{2} \mathrm{SO}_{4}$, and hand thinning (control). Six passes with the tree-width curtain and one, pass with the rotating curtain were used to thin the blossoms. Ammonium thiosulfate (2\%) was applied by handgun to wet the trees to runoff. Flowers per CSA the day of thinning, fruit per CSA 60 DAFB, and mean fruit weight at harvest were determined on three pretagged branches per tree. A freeze during April reduced the crop load, so minimal follow-up hand thinning was required.

1990 Studies. Research on the rotating rope-curtain thinner was continued in 1990. Studies were designed to determine if a smaller-diameter rope $(<3 \mathrm{~cm})$ could thin effectively and to further investigate ways to increase thinning by modifying pruning/training practices. Trials were conducted on 'Redhaven' at Bardane (same as used in 1988 and 1989) and on 'Glohaven' and 'Redskin' at Kearneysville. Thinning with rope diameters of 3.0 and $2.5 \mathrm{~cm}$ was compared to FB and 60-DAFB handthinned controls in the 'Redhaven' study. Thinning with rope diameters of $3.0,2.5$, and $2.0 \mathrm{~cm}$ was compared with unthinned controls on 'Glohaven'. Tree training/pruning was modified in the experiment with 'Redskin'. Treatments included: 1) short tree stature with light pruning, 2) short stature with detailed pruning to eliminate overlapping shoots and narrow branch angles $\left.\left(<45^{\circ}\right), 3\right)$ medium stature with light pruning, and 4) medium stature with detailed pruning. Short-statured trees averaged $1.4 \mathrm{~m}$ high; medium-statured trees averaged $2.2 \mathrm{~m}$ high. Before thinning, flower count $/ \mathrm{cm}^{2}$ averaged 43, 30, 42, and 35 for treatments 1 through 4 , respectively. The rotating curtain with 3-cm rope was compared to unthinned controls. During 1990, FB was the earliest on record, and during the weeks following thinning, $75 \%$ to $100 \%$ of the flowers were killed by a freeze. The number of flowers $/ \mathrm{cm}^{2} \mathrm{CSA}$ was determined on three pretagged branches per tree, but because of the freeze, no further measurements were made. Uniformity of thinning with the rotating thinner was tested by comparing the number of flowers/ $\mathrm{cm}^{2}$ on branches in the lower third and the top third of the canopy. Also, flower density on terminal, middle, and basal fruiting shoot positions was recorded before and after trees were thinned.

Statistical analysis. The 1988 and 1989 treatments were applied to six (Kearneysville) or eight (Bardane) whole-tree replicates in a randomized complete-block design. The 1990 treatments with 'Redhaven' were applied to eight whole-tree replicates in a randomized complete-block design. Treatment of 'Glohaven' and 'Redskin' in 1990 involved six half-tree replicates in a split-plot randomized complete-block design. The data were subjected to analysis of variance. Means were compared by the LSD test.

\section{Results and Discussion}

Tree-width rope-curtain thinner (1988). The modifications in rope diameter and spacing instituted in 1988 improved thinner performance, but multiple passes were still required to achieve maximum thinning. Fruit loads were reduced to three to four fruit $/ \mathrm{cm}^{2} \mathrm{CSA}$ by the best 1988 mechanical thinning treatments (Table 1), whereas the smallest crop load with the 1987 thinner model was nine fruit $/ \mathrm{cm}^{2}$ CSA (Baugher et al., 1988). Based on flower count just after thinning and fruit count following June drop, rope-curtain thinning was equal to hand thinning at FB. Rope-curtain thinning reduced followup hand-thinning time by $40 \%$ and increased fruit weight at harvest $20 \%$ (Table 1). Where rope-curtain thinning was im-

Table 1. Flowers remaining, fruit set, follow-up thinning, and fruit size in 1988 studies on the tree-width rope-curtain thinner. ${ }^{2}$

\begin{tabular}{|c|c|c|c|c|}
\hline $\begin{array}{l}\text { Thinning } \\
\text { method }\end{array}$ & $\begin{array}{c}\text { No. flowers/ } \\
\mathrm{cm}^{2} \text { branch } \\
\mathrm{CSA}^{\mathrm{y}}\end{array}$ & $\begin{array}{c}\text { No. fruit/ } \\
\mathrm{cm}^{2} \text { branch } \\
\mathrm{CSA}^{\mathrm{x}}\end{array}$ & $\begin{array}{c}\text { Follow-up } \\
\text { hand-thinning } \\
\text { time } \\
\text { (min/tree) }\end{array}$ & $\begin{array}{c}\text { Fruit wt } \\
\text { at harvest } \\
\text { (g) }\end{array}$ \\
\hline \multicolumn{5}{|c|}{ Redhaven } \\
\hline FB hand & $8 \mathrm{~b}$ & $5 \mathrm{~b}$ & $7.4 \mathrm{a}$ & $164 \mathrm{~b}$ \\
\hline \multicolumn{5}{|l|}{ Rope curtain +} \\
\hline FB hand & $3 \mathrm{a}$ & $2 a$ & $2.9 \mathrm{a}$ & $177 \mathrm{a}$ \\
\hline Rope curtain & $8 \mathrm{~b}$ & $4 \mathrm{~b}$ & $7.8 \mathrm{a}$ & $176 \mathrm{a}$ \\
\hline 50 DAFB hand & $20 \mathrm{c}$ & $10 \mathrm{c}$ & $19.2 \mathrm{~b}$ & $146 \mathrm{c}$ \\
\hline \multicolumn{5}{|c|}{ Cresthaven } \\
\hline \multicolumn{5}{|c|}{ Open center, moderately pruned } \\
\hline FB hand & $37 \mathrm{~b}$ & $18 \mathrm{a}$ & $0.0 \mathrm{a}$ & $186 \mathrm{a}$ \\
\hline Rope curtain & $37 \mathrm{~b}$ & $19 \mathrm{a}$ & $3.3 \mathrm{~b}$ & $224 \mathrm{~b}$ \\
\hline 50 DAFB hand & $157 \mathrm{~d}$ & $68 \mathrm{c}$ & $6.1 \mathrm{c}$ & $168 \mathrm{a}$ \\
\hline \multicolumn{5}{|c|}{ Open center, detail pruned } \\
\hline FB hand & $10 a$ & $3 \mathrm{a}$ & $0.0 \mathrm{a}$ & $217 \mathrm{~b}$ \\
\hline Rope curtain & $15 \mathrm{ab}$ & 3 a & $1.4 \mathrm{a}$ & $237 b$ \\
\hline 50 DAFB hand & $100 \mathrm{c}$ & $47 \mathrm{~b}$ & $4.5 \mathrm{bc}$ & $186 \mathrm{a}$ \\
\hline \multicolumn{5}{|l|}{ MIA trellis } \\
\hline FB hand & $28 \mathrm{~b}$ & $9 a$ & $1.6 \mathrm{a}$ & $230 \mathrm{~b}$ \\
\hline Rope curtain & $30 \mathrm{~b}$ & $10 \mathrm{a}$ & $2.1 \mathrm{ab}$ & $211 \mathrm{~b}$ \\
\hline $50 \mathrm{DAFB}$ hand & $90 \mathrm{c}$ & $40 \mathrm{~b}$ & $2.5 \mathrm{ab}$ & $162 \mathrm{a}$ \\
\hline
\end{tabular}

${ }^{2}$ Mean separation within columns and headings by LSD, $P=0.05$. 'Determined day of thinning.

xetermined following physiological drop. 
Table 2. Flowers remaining, fruit set, and fruit weight in 1989 studies comparing the tree-width rope curtain to the rotating rope curtain. ${ }^{2}$

\begin{tabular}{|c|c|c|c|}
\hline $\begin{array}{l}\text { Thinning } \\
\text { method }\end{array}$ & $\begin{array}{c}\text { No. flowers } / \mathrm{cm}^{2} \\
\text { branch CSA }\end{array}$ & $\begin{array}{l}\text { No. fruit } / \mathrm{cm}^{2} \\
\text { branch CSA }\end{array}$ & $\begin{array}{l}\text { Fruit wt } \\
\text { at harvest } \\
\text { (g) }\end{array}$ \\
\hline \multicolumn{4}{|c|}{ Redhaven } \\
\hline FB hand & $11 \mathrm{a}$ & $1 \mathrm{ab}$ & $159 \mathrm{~b}$ \\
\hline $\begin{array}{l}\text { Tree-width rope curtain } \\
\text { (six passes) }\end{array}$ & $8 a$ & $1 \mathrm{ab}$ & $174 \mathrm{a}$ \\
\hline Rotating rope curtain & & & \\
\hline (one pass) & $8 \mathrm{a}$ & $1 \mathrm{ab}$ & $165 \mathrm{ab}$ \\
\hline$\left(\mathrm{NH}_{4}\right)_{2} \mathrm{SO}_{4}$ & --- & $2 \mathrm{bc}$ & $163 a b$ \\
\hline $60 \mathrm{DAFB}$ hand & $26 \mathrm{~b}$ & $3 c$ & $147 c$ \\
\hline \multicolumn{4}{|c|}{ Loring } \\
\hline FB hand & $14 \mathrm{a}$ & 0 & \\
\hline $\begin{array}{l}\text { Tree-width rope curtain } \\
\text { (six passes) }\end{array}$ & $15 \mathrm{a}$ & 0 & \\
\hline $\begin{array}{l}\text { Rotating rope curtain } \\
\text { (one pass) }\end{array}$ & $14 \mathrm{a}$ & 0 & --- \\
\hline $60 \mathrm{DAFB}$ hand & $20 \mathrm{~b}$ & 0 & - \\
\hline \multicolumn{4}{|c|}{ Cresthaven } \\
\hline FB hand & $14 \mathrm{~b}$ & $0.4 \mathrm{a}$ & --- \\
\hline $\begin{array}{l}\text { Tree-width rope curtain } \\
\text { (six passes) }\end{array}$ & $13 \mathrm{~b}$ & $0.5 \mathrm{a}$ & --- \\
\hline $\begin{array}{l}\text { Rotating rope curtain } \\
\text { (one pass) }\end{array}$ & $10 \mathrm{a}$ & $0.2 \mathrm{a}$ & $\cdots$ \\
\hline $60 \mathrm{DAFB}$ hand & $19 \mathrm{c}$ & $1.0 \mathrm{~b}$ & $\cdots$ \\
\hline
\end{tabular}

${ }^{2}$ Mean separation within columns and headings by LSD, $P=0.05$. yetermined day of thinning.

${ }^{x}$ Determined following physiological June drop.

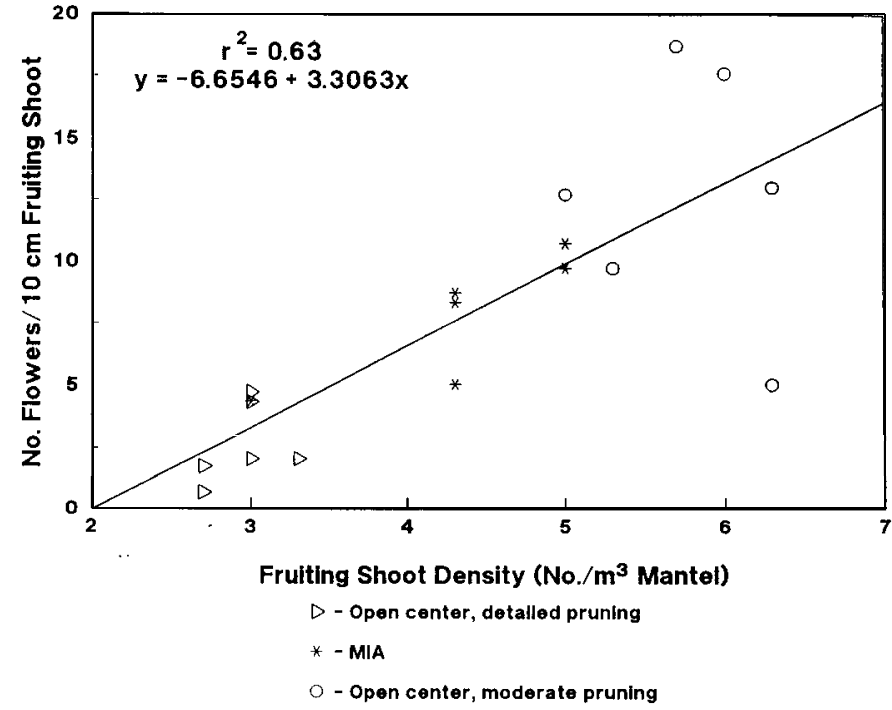

Fig. 2. Regression analysis on the relationship between the number of flowers $/ 10 \mathrm{~cm}$ of shoot following mechanical thinning and shoot density. Measurements from three, $0.3-\mathrm{m}^{3}$ regions in each of six replicates per training/pruning treatment. proportions of basal, middle, or terminal flowers between thinned and unthinned shoots (Fig. 3D). The results further support the positive effect of decreased shoot density on thinner performance.

Potential commercial application. Numerous studies have demonstrated the effects of early and/or degree of thinning on increasing fruit size, hastening the rate of maturation, and improving fruit quality (Byers and Lyons, 1985; Havis, 1962; Johnson and Handley, 1989; Weinberger, 1941). The studies have generally shown that profits are increased due to improved fruit packout and earlier harvests. During our 3 years of research with mechanical thinning of peaches, we have measured increases in fruit size ranging from $10 \%$ to $20 \%$, depending on year and cultivar. Mechanical thinning also affords the grower the opportunity to decrease a major growing expense--that of hand thinning. Our studies have shown that hand-thinning requirement can be reduced by $40 \%$ to $100 \%$, which would be a saving of $\$ 30$ to $\$ 80 /$ ha under mid-Atlantic conditions, after the cost of rope-thinning is deducted. Since thinning in the lower third of the tree canopy is less than in the top two-thirds of the canopy, it is likely that follow-up thinning will be required. Additional benefits of rope-curtain bloom thinning include ease of construction, predictability, and the avoidance of chemicals and the associated regulations. Disadvantages of mechanical bloom thinning include the potential for frost following thinning and the possibility that the incidence of Cytospora canker might be increased. However, in the 'Redhaven' block where mechanical thinning has been used for three consecutive years, we saw no effect on canker incidence. Future studies need to determine if 1) effective bloom removal can be accomplished with the rotating thinner after the danger of frost is past and 2) precautions are needed to prevent infections by Cytospora species. 
A

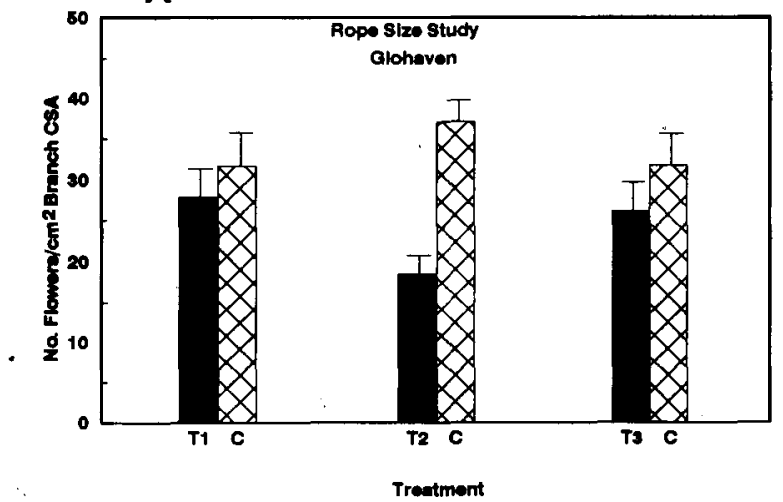

C

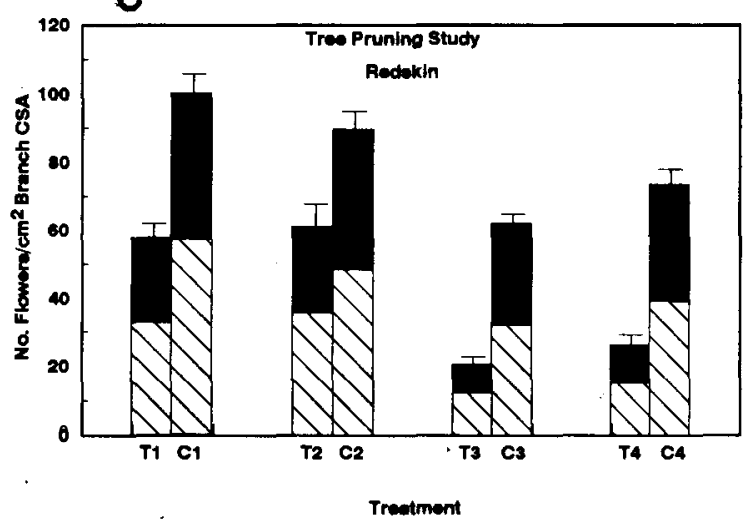

B

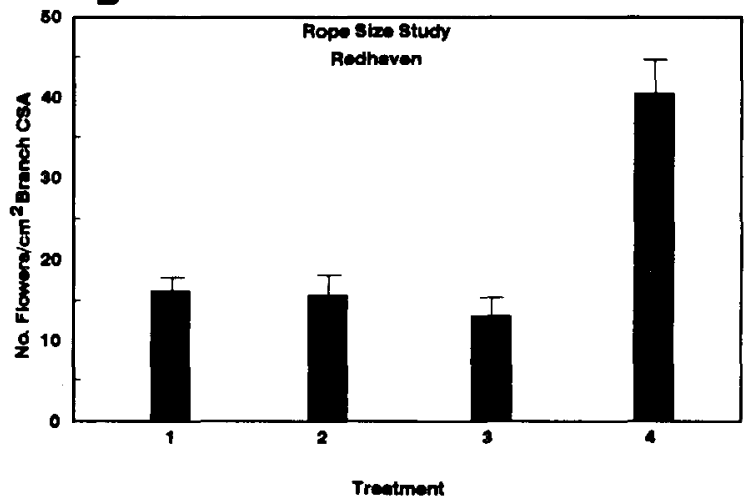

D

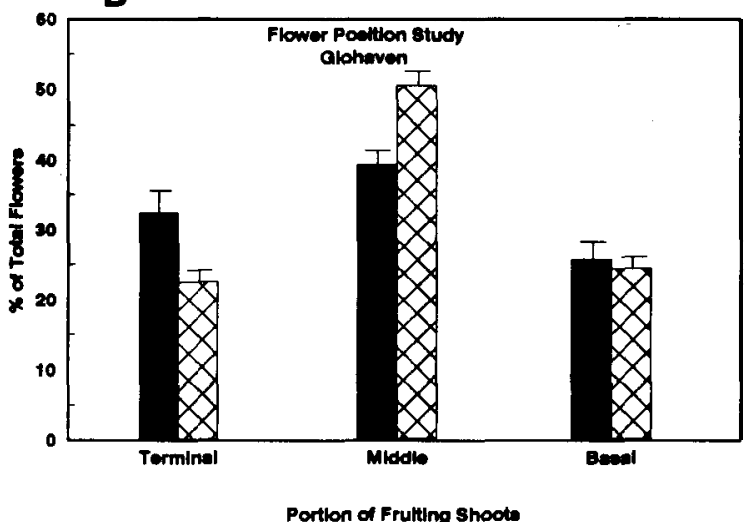

Fig. 3. (A) Comparison of rotating rope curtains with 2.0- (T1), 2.5- (T2), and 3.0 (T3)-cm-diameter ropes to unthinned controls (C) (n = 18). (B) Comparison of rotating rope curtain with $3.0-\mathrm{cm}$-diameter rope (2) and rotating rope curtain with 2.5 -cm-diameter rope (3) to bloom hand-thinned (1) and unthinned controls $(4)(\mathrm{n}=24)$. (C) Influence of tree stature and level of pruning $(1=$ short, light pruning; $2=$ medium, light pruning; 3 = short, detailed pruning; 4 = medium, detailed pruning) on performance of rotating rope curtain (measurements from pretagged branches in lower third of canopy $(\mathbb{N}), n=6$, compared to tagged branches in all heights $(\mathbb{D}), \mathrm{n}=18$, of canopy). (D)

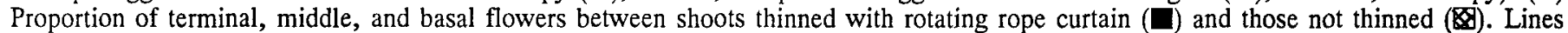
above bars represent SE.

\section{Literature Cited}

Baugher, T. A., K.C. Elliott, S.H. Blizzard, S.I. Walter, and T.A. Keiser. 1988. Mechanical bloom thinning of peach. HortScience 23:981-983.

Byers, R.E. 1989. High pressure water stream bloom thinning and $\mathrm{GA}_{3}$ sprays on flower bud numbers and distribution in peach trees. Annu. Rpt. State Hort. Soc. Mich. 119.

Byers, R. E., D.H, Carbaugh, and C.N. Presley. 1990. The influence of bloom thinning and $\mathrm{GA}_{3}$ sprays on flower bud numbers and distribution in peach trees. J. Hort. Sci. 65:143-150.

Byers, R.E. and C.G. Lyon, Jr. 1985. Peach flower thinning and possible sites of action of desiccating chemicals. J. Amer. Soc. Hort. Sci. 110:662-667.
Havis, A.L. 1962. Effect of time of fruit thinning of 'Redhaven' peach. Proc. Amer. Soc. Hort. Sci. 80:172-176.

Hutton, R.J. and L.M. McFadyen. 1987. Relative productivity and yield efficiency of canning peach trees in three intensive growing systems. HortScience 22:552-560.

Johnson, R.S. and D.F. Handley. 1989. Thinning response of early-, mid-, and late-season peaches. J. Amer. Soc. Hort. Sci. 114:852855.

Myers, S.C. 1986. Effect of thinning on the subsequent development of fruit, shoots and flower buds of peach. HortScience 21:680. (Abstr.)

Weinberger, J.H. 1941. Studies on time of peach thinning from blossoming to maturity. Proc. Amer. Soc. Hort. Sci. 38:137-140. 